\title{
Effect of Multiple Water Impinging Jet Array on Quenching Hot Rotary Hollow Cylinders
}

\author{
Mohammad Jahedi ${ }^{1}$, Bahram Moshfegh ${ }^{1,2}$ \\ ${ }^{1}$ Department of Building Engineering, Energy Systems and Sustainability Science, University of Gävle \\ 801 76, Gävle, Sweden \\ Mohammad.jahedi@hig.se; bahram.moshfegh@hig.se \\ ${ }^{2}$ Department of Management and Engineering, Linköping University \\ 583 30, Linköping, Sweden
}

\begin{abstract}
Experimental study has been carried out to investigate transient quenching of a rotary hollow cylinder by water impinging jets in multiple jet arrays. Subcooled water jets $\left(\Delta T_{\text {sub }}=55-85 \mathrm{~K}\right)$ were placed into two types of nozzle arrays: 1-row and 2-row in-line array. The flow rate of water jets varied from 2.7 to $10.9 \mathrm{~L} / \mathrm{min}$, impinging on hot rotary cylinder $\left(T_{i}=600^{\circ} \mathrm{C}\right)$ with rotation speed $10-50$ $\mathrm{rpm}$ and different curvature ratio $\left(D_{o} / d=12,19\right.$ and 24). The local average and maximum boiling heat transfer at water jet's stagnation point revealed effect of studied quenching parameters and multiple jet arrays in the boiling heat transfer. The result showed among the studied parameters, jet's flow rate and curvature ratio influenced heat transfer in all the boiling regimes. Rotation speed was effective in film and transition boiling regime and strong effect of subcooling was captured in the transition boiling regime. The characteristics of maximum heat flux point in the boiling curve were found to be dependent on the studied quenching parameters as well as array of nozzles. Multiple jet arrays had effect on the spatial variation and rate of boiling heat transfer on quenching surface. Higher area-averaged and maximum surface heat flux was obtained by 2-row array while array's total flow rate was kept constant. It was found that by impinging constant water flow rate into the jets, 2-row array with twice the number of impinging jets enhanced heat transfer significantly in film and transition boiling regime in combination with other quenching parameters.
\end{abstract}

Keywords: Multiple jet arrays, Transient boiling, Rotating surface, Inverse heat conduction problem, Quenching, Water impinging jet

\section{Introduction}

More advanced controllable quenching techniques are of interest in the metal industry to optimize the efficiency of cooling processes resulting in improved material properties and quality. Among the cooling methods that are used, quenching hot metal surfaces by water impinging jet is one of the best-known and effective methods. In solid-liquid contact over the quenching surface, boiling phenomena occur and introduce various boiling regimes during the cooling process.

In the water impinging technique, the water jet's flow is impinged toward the hot surface and experiences constraint by the surface resulting in changing flow direction into a wall-jet shape. In the first moments, water flow is deflected to surroundings due to very large temperature difference between solid and liquid. The surface temperature around the stagnation point of impingement drops very fast and a circular wetted zone is formed over the surface. By passing the resident time [1], the wetted zone surrounding the stagnation region of water jet starts to grow while its edge experiences nucleate and transition boiling condition [2]. Further in radial distance from stagnation point, annular transition zone (also known as wetting front region [3]) exists where water flow is splashed away as water drops are in contact with the hot dry zone [4].

In the study of boiling heat transfer and its characteristics on quenching a flat surface by single water impinging jet, various parameters need to be considered. Some of the reported important parameters are liquid subcooling [5], impinging jet diameter [6,7], single water jet flow rate [5, 8], material properties of quenching surface [9], initial temperature of quenching [10] and jet-to-surface spacing [5, 8]. In real conditions in the metal industry, quenching is often applied on moving hot metal product on the run-out table which introduces surface moving speed as an additional parameter [11]. This causes the wetted and wetting front $(W F)$ region to become asymmetric by hydraulic jump in one side of wetting front region [12]. In practice, in order to apply the water jet quenching technique, several water jets are needed to be placed in multiple array to cover large hot surfaces. Vakili and Gadala [13] performed quenching experiment on a moving hot flat surface by 
in-line and staggered arrays of nozzles and showed that lowest spatial variation of cooling occurred with staggered arrays of jets. They also reported lower surface heat flux by increasing surface moving speed in high entry temperature.

Despite the good literature on the quenching of hot flat surfaces, few research studies performed quenching on a cylinder surface by single water jet. Quenching such geometry represents boiling phenomena over a convex surface. In practice, rotation exists on run-out table which introduces new features in the hydrodynamic of boiling. The surface experiences cooling under the wetted and wetting front regions and then enters a dry zone where temperature recovery occurs due to internal conduction heat transfer inside material until the surface approaches the wetted and wetting front region in the next revolution cycle. This characteristic leads to cyclic fluctuation of heat flux depending on rotation speed of cylinder and its footprint is found in the boiling curve $[14,15]$. The similarity between growth of wetted region and wetting front over rotary cylinder and moving flat surface is the hydraulic jump on one side and stretched wetted and wetting front regions in the moving direction $[16,17]$.

Similar to quenching of large flat surface, multiple jet array is required for quenching of large and long tubes and bars in practice. There are only a few studies that have investigated hydrodynamics of boiling phenomena and heat transfer characteristics affected by the quenching parameters. Jahedi and Moshfegh [18] studied quenching of a rotary cylinder by 1row array of subcooled water jets and reported temperature and cooling rate variation near the surface influenced by water jet flow rate, subcooling, impingement impact angle, rotation speed, initial quenching temperature and jet-to-jet spacing, which is the new parameter in the quenching technique. Smaller spacing between jets $(S / d \leq 4)$ provides more uniform cooling rate over the quenching surface. But larger spacing creates better interaction between neighbor jets, and results in high cooling rate region in this zone.

In the interaction zone, $W F$ of neighboring jets collide with each other thus forming upward fountain flow, a mechanism to discharge $W F$ from the surface. In a recent study, Jahedi and Moshfegh [19] investigated hydrodynamic phenomena of interactions between water jets over rotary cylinder quenched by 1-row and 2-row in-line multiple jet arrays and presented two types of interactions between jets; lateral upwash flow is formed by $W F$ interaction of neighbor jets in 1-row array and secondary interaction occurs in 2-row configuration of nozzles between $W F$ of jets in adjacent rows which is called longitudinal upwash flow. They reported the discharged mechanism behavior led to high surface heat flux in the lateral upwash flow zone, which is in agreement with the previous studies on flat surface quenching [13, 20]. They also studied quenching parameters' influence on average heat transfer over quenching surface, local heat transfer at stagnation point of water jet and lateral upwash flow point in the 1-row multiple jet array.

From the above-mentioned literature, only a few studies have been carried out on quenching of convex surfaces by multiple pitch of water jets (1-row pitch). Therefore for this study, authors intended to present the experimental results on 1row and 2-row in-line arrays of water jets on the quenching of rotary cylinder (convex surface) to provide better understanding of the effect of multiple arrays together with quenching parameters on the local boiling heat transfer.

\section{Experimental Method}

\subsection{Experimental Setup}

Fig. 1 presents a schematic of the experimental setup and nozzle configuration with respect to temperature measurement points. 1-row and 2-row in-line multiple jet arrays of subcooled water impinging jets were used to quench a hollow cylinder. Test specimen was rotated during the quenching experiment to mimic actual condition of run-out table in industry. Temperature data was acquired by grounded N-type thermocouple with $0.75 \mathrm{~mm}$ probe diameter mounted in two different depths $\left(R_{1}\right.$ and $\left.R_{2}\right)$ in the hollow cylinder near the quenching surface $\left(R_{3}\right)$. DAQ system connected to LabVIEW program monitored and recorded temperature and water flow rate signals during the experiment. Water temperature in the tank was regulated by water cooler and heater in an internal circulation. Regulation and measurement of water flow rate in the piping system was done by water pump and magnetic flow meter respectively. Rotation speed of hollow cylinder was adjusted by controller of servo motor. When initial quenching temperature reached slightly above $600^{\circ} \mathrm{C}$ in the heating process by induction heater, the LabVIEW program was able to send pulse signal to solenoid valves to switch water flow from internal circulation toward multiple arrays of impinging jets. Full description of experimental process of the quenching has been reported by Jahedi and Moshfegh [18].

In this study, effect of various parameters of quenching was investigated on cooling of the rotary hollow cylinder impinged by 1-row and 2-row array of multiple water impinging jets. Table 1 shows designed range of the parameters investigated in this study. 


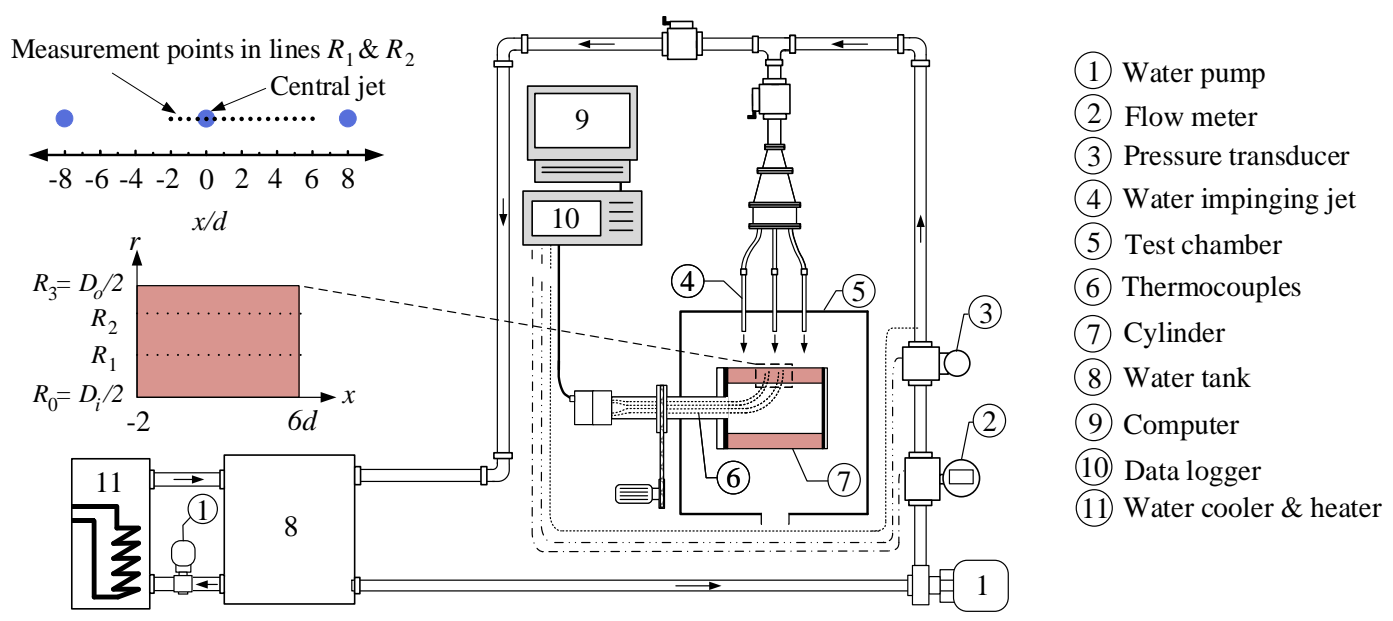

Fig. 1: Schematic of experimental set-up and orientation of temperature measurement points with respect to nozzle configuration.

Table 1: Designed parameters in the experimental study.

\begin{tabular}{clc}
\hline Parameter & Range & Unit \\
\hline$Q$ & $2.7,5.4,10.9$ & $\mathrm{~L} / \mathrm{min}$ \\
$\Delta T_{\text {sub }}$ & $55,75,85$ & $\mathrm{~K}$ \\
$D_{o} / d$ & $12,19,24$ & - \\
$\omega$ & $10,30,50$ & $\mathrm{rpm}$ \\
$N$ & 1,2 & - \\
array & In-line & -
\end{tabular}

The round jet diameter $(d)$ was $8 \mathrm{~mm}$ with jet-to-wall spacing $H / d=1.5$, jet-to-jet spacing $S / d=6$ and the angles $\alpha$ and $\theta$ in the configuration were 45 and $90^{\circ}$, respectively. The hollow cylinder's outer diameter $\left(D_{o}\right)$ was 96,152 and $192 \mathrm{~mm}$ with the outer to inner diameter ratio $D_{o} / D_{i}=1.56,1.59$ and 1.54 respectively and length $L=173 \mathrm{~mm}$, see Fig. $1 . N$ stands for number of rows an appellation Row A was used in the 1-row pitch and Row A and B were applied in the 2-row in-line array. The maximum uncertainty of calibrated thermocouple sensor and data acquisition system was $\pm 1.1 \%$ at a temperature of $100^{\circ} \mathrm{C}$. The uncertainty of thermocouple sensor location, water flow rate and water temperature were $\pm 4.6, \pm 1.4$ and $\pm 4.7 \%$, respectively.
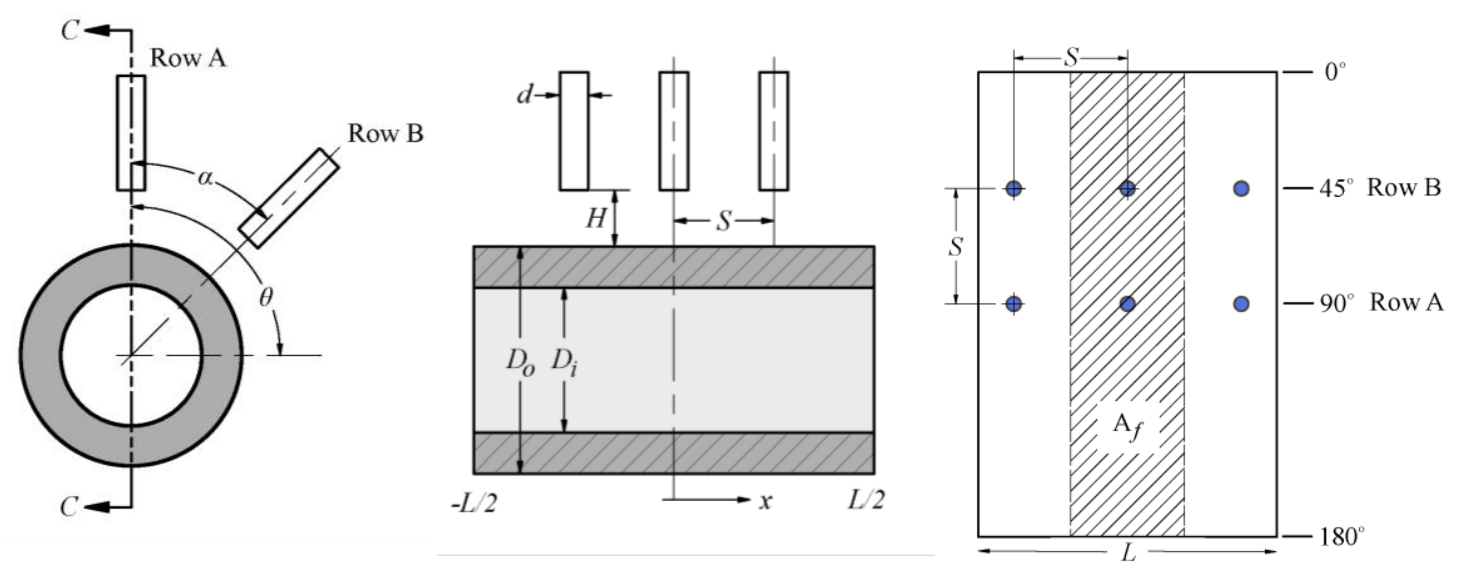

Fig. 2: Configuration of multiple impinging jets arrays; 1-row array (Row A) and 2-row array (Row A and B).

\subsection{Data Reduction}

In order to understand hydrodynamic phenomena of boiling and effect of the parameters on quenching heat transfer, studying the surface heat flux and temperature is of interest since boiling occurs on quenching surface when liquid and solid 
interact with each other. Surface temperature measurement is challenging as temperature sensors may disturb water flow field on the surface or cannot withstand harsh conditions during the heating and cooling process. One way to overcome this problem is to apply an inverse solution technique to determine the surface temperature and heat flux. In this study, the generalized minimal residual method (GMRES) [21] developed by Jahedi, et al. [15] for application of quenching rotary hollow cylinder by water impinging jets was used. In this inverse problem technique, recorded interior temperature data of cylinder at two different depths from quenching surface (line $R_{1}$ and $R_{2}$ ) is applied as input into the GMRES method to predict surface temperature and heat flux at line $R_{3}$, see Fig. 1 .

In order to calculate average heat transfer in the boiling regimes, Leidenfrost temperature was calculated based on reported value by Jahedi and Moshfegh [19]. Local maximum heat flux $(M H F)$ and corresponding temperature $\left(T_{\mathrm{MHF}}\right)$ are obtained from boiling curve (Fig. 3) and time to reach this point $\left(t_{\mathrm{MHF}}\right)$ is extracted from the heat flux graph. Since $M H F$ is shifted from nucleate boiling toward higher temperature level by some parameters, the corresponding temperature to $C H F$ in onset of nucleate regime is picked up from the boiling curve of experiments where no higher heat flux is captured in lower temperatures in the nucleate regime.

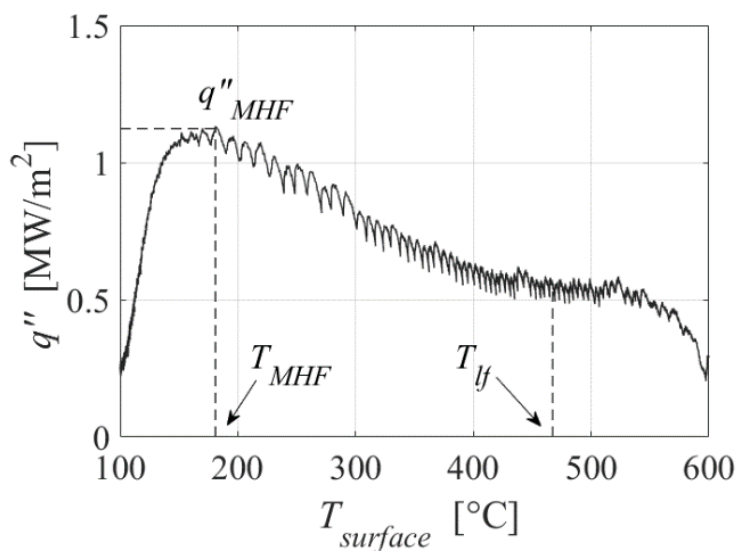

Fig. 3: Boiling curve at stagnation point of central jet in 1-row array pitch $\left(Q=5.4 \mathrm{~L} / \mathrm{min}, \omega=50 \mathrm{rpm}, \Delta T_{s u b}=55 \mathrm{~K}, D_{o} / d=24\right.$, $N=1, S / d=6, H / d=3, T_{i}=600^{\circ} \mathrm{C}$.

\section{Result and Discussion}

\subsection{Multiple Array of Jets}

In the investigation of the effect of multiple array of jets on the heat transfer behavior, total flow rate $Q_{\text {total }}=32.5$ $\mathrm{L} / \mathrm{min}$ is remained constant. Twice the number of nozzles in 2-row compared to 1-row array with $Q_{\text {total }}=32.5 \mathrm{~L} / \mathrm{min} \mathrm{leads}$ to $50 \%$ lower flow rate on each water jet in the array while impinging area on quenching surface $\left(A_{f}\right)$ is expanded. In the investigation on local and area-averaged heat transfer, Fig. 4(a) presents enhancement of both area-averaged and maximum heat flux $\left(q^{\prime \prime}\right.$ avg and $q^{\prime \prime}$ max $)$ over $A_{f}$ by larger $N$ in 2-row array with $50 \%$ lower jet's flow rate. $3 D$ contour plot of surface heat flux $q$ " provides interesting information (Fig. 4(b) and 3(c)) where central impinging jet and upwash flow point are located at $x / d=0$ and 3, respectively. In 1-row array (Fig. 4(b)), a region with very low cooling rate at the onset of quenching at upwash flow region starts to grow in size and time duration until collision of $W F$ flows and formation of upwash flow [19] to increase $q^{\prime \prime} u p w$. The result reveals that the extended impinging area over $A_{f}$ has strong influence on heat transfer. Higher $q^{\prime \prime}{ }_{a v g}$ (Fig. 4(a)) by $N=2$ compensates for the negative effect of $W F$ with smaller propagation velocity to approach the upwash flow zone in the 2-row array, resulting in shorter time to create peak region in $2<x / d<4$. The expanded impinging area also has an effect on local boiling heat transfer where regions with peak heat flux around stagnation and upwash flow point $\left(x_{s t g}\right.$ and $\left.x_{u p w}\right)$ are distinguished more clearly in 2-row array impingement. By these evaluations, one can conclude that in the case of constant total flow rate, there is a relation between number of rows $(N)$ in the array and jet's flow rate $(Q)$ in terms of local heat transfer rate and magnitude of spatial variation of boiling heat transfer over $A_{f}$ during quenching time; larger $N$ and lower $Q$ increases boiling heat transfer rate over $A_{f}$ and reduces quenching time significantly. 


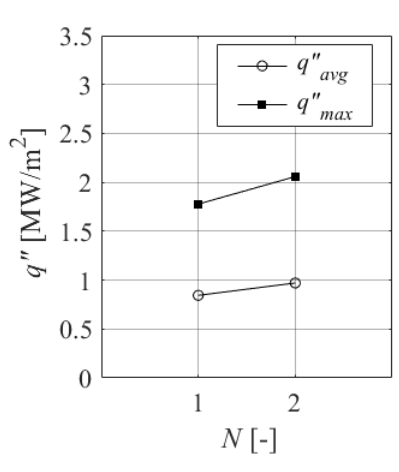

(a)

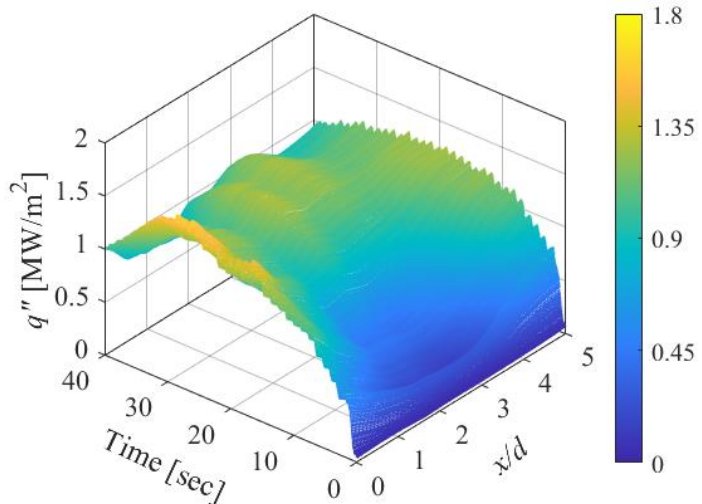

(b)

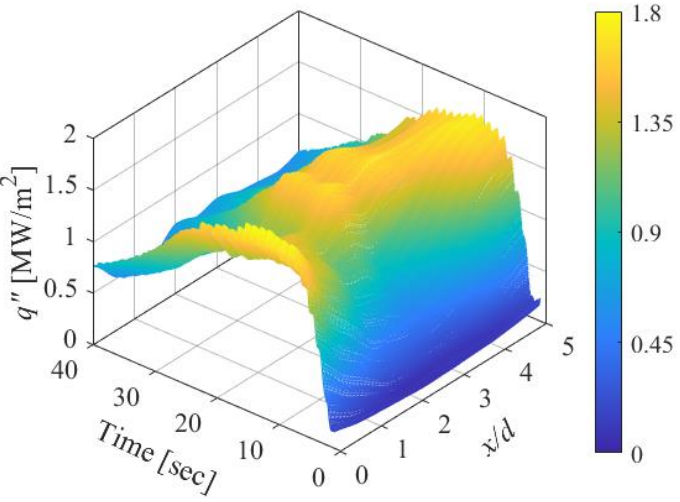

(c)

Fig. 4: Effect of multiple jet arrays on heat transfer in experiments with $Q_{\text {total }}=32.5 \mathrm{~L} / \mathrm{min}$, (a) average and maximum surface heat flux over $A_{f}$; (b) 1-row array; (c) 2-row in-line array; $\left(T_{i}=600^{\circ} \mathrm{C}, Q_{\text {total }}=32.5 \mathrm{~L} / \mathrm{min}, \omega=50 \mathrm{rpm}, \Delta T_{\text {sub }}=75 \mathrm{~K}, D_{o} / d=24\right)$.

\subsection{Water Jet Flow Rate}

The rate of water flow from each individual impinging jet $(Q)$ has been of interest in the boiling heat transfer in previous studies. It is important to note that since single jet's diameter is constant in this study, the total area of nozzles in the array is calculated based on the number of rows $(N)$, and $Q_{\text {total }}$ becomes dependent on $Q$ and $N$. The result in Fig. 5(a) reveals that $Q$ has noticeable influence on local boiling heat transfer, $q^{\prime \prime}{ }_{\text {avg }}$ at $x_{\text {stg }}$ in all boiling regimes; higher $Q$ enhances $q^{\prime \prime}$ avg monotonically in 1-row and 2-row multiple arrays in good agreement with similar reported behavior in quenching rotary cylinder $\left(D_{o} / d=12\right)$ by 1-row array [19].
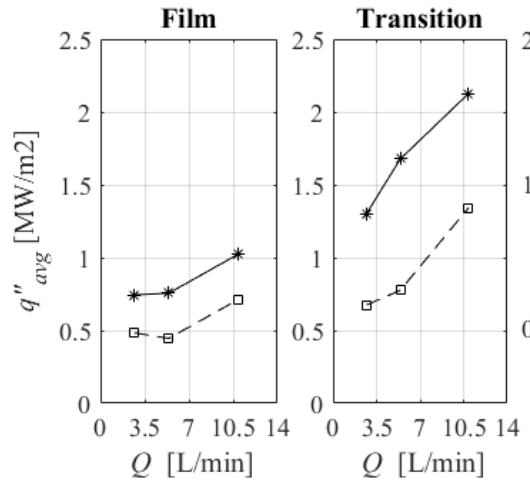

(a)

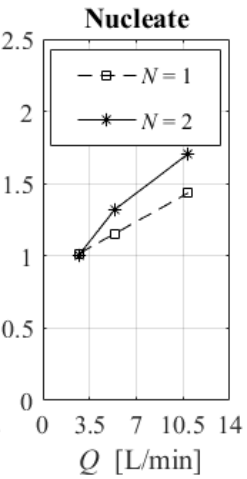

$Q[\mathrm{~L} / \mathrm{min}]$

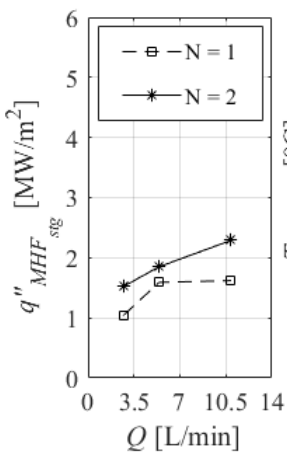

$Q[\mathrm{~L} / \mathrm{min}]$

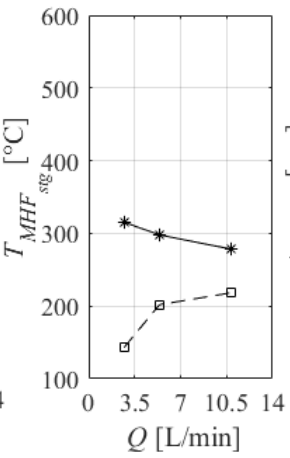

(b)

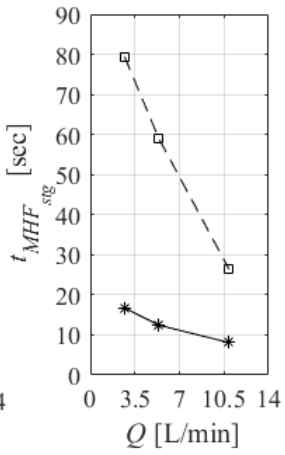

Fig. 5: Local boiling heat transfer's variation at $x_{\text {stg }}$ by water jet's flow rate (a) $q^{\prime \prime}{ }_{a v g}$; (b) $M H F$ parameters $\left(T_{i}=600^{\circ} \mathrm{C}, \omega=50\right.$ rpm,

$$
\left.\Delta T_{\text {sub }}=75 \mathrm{~K}, D_{o} / d=24\right) \text {. }
$$

Noticeable result is obtained by looking into effect of pitch and jet flow rate while $Q_{\text {total }}$ remains constant. Increased number of rows in pitch $N=2$ enhances $q^{\prime \prime}{ }_{\text {avg }}$ by an average $90 \%$ compared to $45 \%$ by two times more $Q$ in 1-row array at $x_{s t g}$ in the transition regimes. But in the nucleate boiling strong effect of pitch vanishes and the enhancement of average heat flux becomes $10 \%$ by greater $N$ compared to $19 \%$ by two times $Q$ in 1 -row array. These values become $56 \%$ and $27 \%$ enhancement by $N$ and $Q$ respectively in the film boiling. This result reveals two times more effect of pitch than $Q$ in the film and transition boiling and less effect in the nucleate boiling regime. Result in Fig. 5(b) shows higher jet flow rate increases $q_{M H F}$ at $x_{s t g}$ in both arrays and this is in agreement with the result of single jet experiment [16]. Temperature corresponding to $M H F$ increases by higher $Q$ in the 1-row array. This is caused by higher jet flow rate which creates shoulder of flux [22] in the transition boiling and therefore $M H F$ occurs at higher temperature in the boiling curve. The $T_{M H F}$ is effected differently where higher $Q$ has little effect to move the $M H F$ point toward lower temperature in boiling curve. The 
time to reach $M H F$ point $\left(t_{M H F}\right)$ decreases drastically by higher jet flow rate in both arrays of jets. The reduction in the time becomes more pronounced in the 1-row jets due to creation of shoulder of flux in transition boiling by higher $Q$ which leads to shorter time to reach $M H F$ at $x_{s t g}$. In agreement with the result in section 3.1, the result shows more dominant influence of multiple array than single jet flow rate $(Q)$ in the local boiling heat transfer.

\subsection{Water Subcooling}

Fig. 6(a) presents result of investigation on $q^{\prime \prime}{ }_{\text {avg }}$ at $x_{\text {stg }}$ influenced by water subcooling $\left(\Delta T_{\text {sub }}\right)$. In the general trend, a slight increase is seen on local average heat flux in the film boiling. In the transition regime, dependency of $q^{\prime \prime}$ avg on subcooling is observed more clearly; enhancement of $q^{\prime \prime}{ }_{\text {avg }}$ by higher $\Delta T_{\text {sub }}$ is more pronounced in $75 \leq \Delta T_{\text {sub }}$ in 1 -row array. Similar to the film boiling, slight enhancement is captured in the nucleate boiling by subcooling in both impingement arrays. The different behavior of $q^{\prime \prime}$ avg in the boiling regimes is in agreement with previous study on single jet by Gradeck, et al. [23] and 1-row array by Jahedi and Moshfegh [19]. In the study of multiple jet array shown in Fig. 6(a), one can notice that enhancement of $q^{\prime \prime}$ avg is significant in the film and transition boiling regimes, but little increase is captured in the nucleate regime by $N=2$.

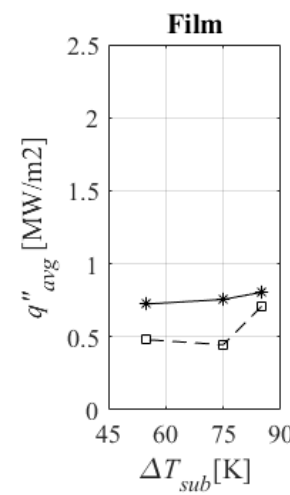

$\Delta T_{s u b}[\mathrm{~K}]$

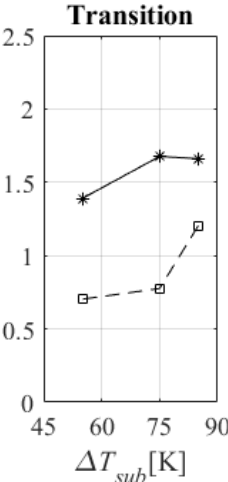

(a)

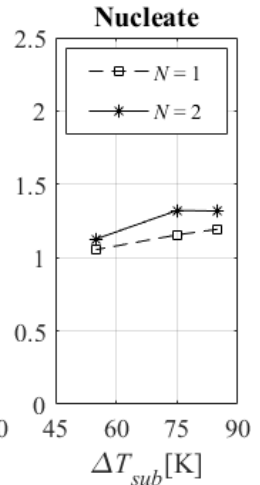

$\Delta T_{s u b}[\mathrm{~K}]$

Fig. 6: Subcooling's effect on local boiling heat transfer at $x_{\text {stg }}$ : (a) $q^{\prime \prime}{ }_{\text {avg }}$; (b) $M H F$ parameters $\left(T_{i}=600^{\circ} \mathrm{C}, \omega=50 \mathrm{rpm}, Q=5.4\right.$ $\left.\mathrm{L} / \mathrm{min}, D_{o} / d=24\right)$.

In the study of subcooling influence on maximum local heat transfer, Fig. 6(b) shows higher $\Delta T_{\text {sub }}$ increases heat flux in agreement with reported result of quenching rotary cylinder by single and 1-row arrays water jet [16, 19]. Enhancement of $q^{\prime \prime}{ }_{M H F}$ by higher $Q_{\text {total }}$ in 2-row pitch again explains the importance of total flow rate and multiple jet configuration on the local boiling heat transfer. The temperature corresponding to $M H F$ remains nearly at low level in 1-row array while $T_{M H F}$ is increased by higher subcooling in 2-row array. This interesting result shows that higher subcooling and $Q_{\text {total }}$ move the position of $M H F$ toward higher temperatures in the boiling curve. The propagation velocity of $W F$ is decreased gradually by lower subcooling [24] and this means that the stagnation point experiences the boiling regimes for a longer time by lower subcooling, causing increase of $t_{M H F}$. It is interesting to see that higher $Q_{\text {total }}$ in 2-row array suppresses the $t_{M H F}$ severely compared to 1-row pitch.

\subsection{Rotation Speed}

The new parameter in the hydrodynamic phenomena of boiling in presence of rotary test specimen is rotation speed of the cylinder $(\omega)$ corresponding to surface moving speed. Lower rotation speed interacts less with the wetted and wetting front zone and disturbs the hydraulic jump of $W F$ less in each cycle of revolution. Surface also experiences longer cooling time under wetted and wetting front zone, but on the other hand, time to pass the dry zone is also greater in each revolution and lower passing frequency through the wet zone is obtained. Higher heat transfer is achieved in prior revolutions by less disturbed water flow over surface and longer time to pass wet zone in lower $\omega$ in the film boiling regime, see Fig. 7(a). In the transition boiling, heat transfer variation is little in 1-row pitch and becomes less at both small and large rotation speeds. Added extra row of nozzles in 2-row array extends the wet zone over $A_{f}$ and higher $\omega$ shorten the time for surface to approach the wet zone on the next revolutions. And these two parameters may damp the negative effect of water flow agitation by 
higher $\omega$ in the transition boiling and increase the heat transfer slightly. Similar behavior is captured by both arrays on heat transfer result in the nucleate boiling regime; both multiple jets arrays provided higher $q^{\prime \prime}$ avg in the mid-range rotation speed $(\omega=30 \mathrm{rpm})$ which may be due to less negative interaction effects of both high and low revolution speeds at this speed level. Comparing result of 1-row and 2-row arrays at $q^{\prime \prime}{ }_{\text {avg }}$ in various rotation speeds shows significant increase of $q^{\prime \prime}$ avg by larger $N$ in the multiple jet array in the film and transition regimes in the presence of rotation speed variation and unaffected local heat transfer at $x_{\text {stg }}$ in the nucleate boiling.

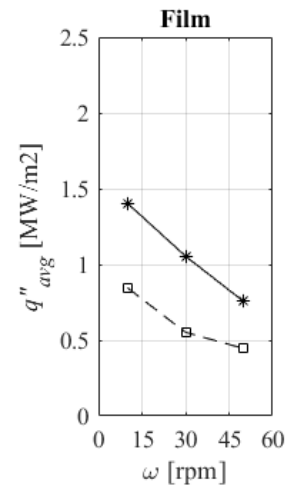

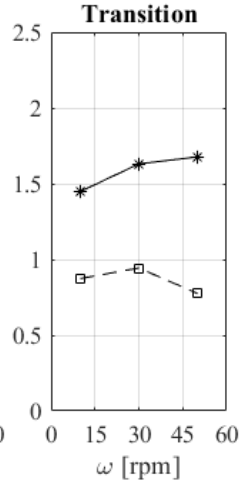

(a)

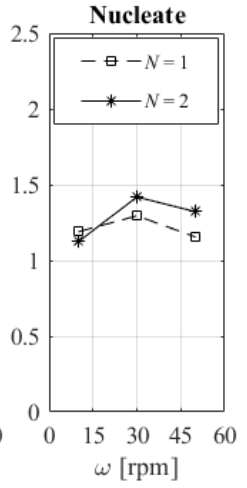

$\begin{array}{lll}15 \quad 30 & 45 \\ \omega & {[\mathrm{rpm}]}\end{array}$

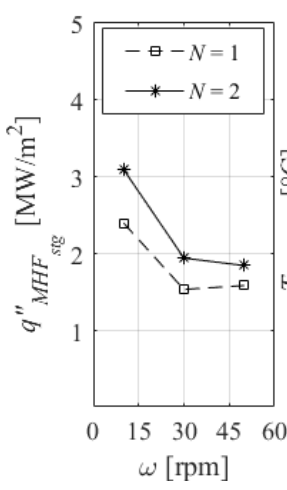

$\omega[\mathrm{rpm}]$

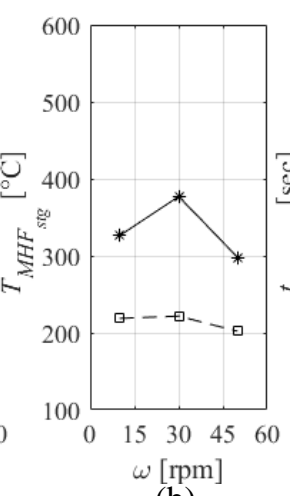

(b)

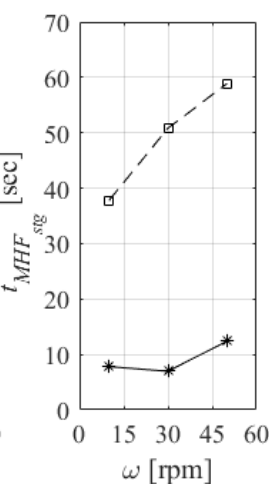

$\omega[\mathrm{rpm}]$

Fig. 7: Effect of cylinder rotation speed on local boiling heat transfer at stagnation point of water jet: (a) $q^{\prime \prime}{ }_{\text {avg }}$; (b) $M H F$ parameters

$$
\left(T_{i}=600^{\circ} \mathrm{C}, \omega=50 \mathrm{rpm}, Q=5.4 \mathrm{~L} / \mathrm{min}, D_{o} / d=24\right) .
$$

The result in Fig. 7(b) presents significant effect of $\omega$ on the MHF parameters. As discussed above, higher heat transfer is achieved at lower rotation speed by longer time of passage through wetted zone and cooling by less disturbed water impinging jets in prior revolutions. As a result, greater $M H F$ occurs in shorter time $\left(t_{M H F}\right)$ in both arrays of nozzles. The variation of $T_{M H F}$ shows higher frequency of passing the wet zone at higher rotation speed shifts $M H F$ point into smaller temperature slightly for $\omega>30 \mathrm{rpm}$ in the boiling curve at $x_{\text {stg }}$ in both pitches.

\subsection{Curvature Ratio}

The curvature ratio $\left(D_{o} / d\right)$ is defined based on ratio between cylinder and jet size and since $D_{i}$ is dependent on $D_{o}$ in this study, bigger cylinder has larger thickness. In the film boiling regime, higher heat flux is seen by smaller hollow cylinders (Fig 8(a)). By investigation of boiling curves in Fig 8(b), it is found that magnitude of heat flux enhancement is stronger in film boiling with smaller $D_{o} / d$. In the transition regime, a similar trend is seen with $D_{o} / d$ for smaller cylinder sizes. In the nucleate boiling regime at $x_{s t g}$, average heat flux is enhanced by larger $D_{o} / d$, in general trend which it may be due to the fact that more mass in cylinder with larger $D_{o} / d$ transfers more heat flux toward surface when surface experiences nucleate boiling. In general, 2-row pitch raises magnitude of heat flux over $A_{f}$ in the film and transition boiling, and nucleate boiling regime appears unaffected by multiple jet array.

In the study of local maximum heat flux, authors found $q^{\prime \prime}{ }_{M H F}$ and $T_{M H F}$ decreases with larger $D_{o} / d$ and the time corresponding to $M H F$ point increases generally. The result showed that pitch $N=2$ enhances $M H F$ characteristics compared to $N=1$. The stagnation point's boiling curve at different cylinder sizes in Fig 8(b) shows clearly the cyclic variation of heat flux and temperature in revolutions by passing wetted and dry zones is suppressed with larger $D_{o} / d$. This is because size of quenching area and thickness of hollow cylinder become larger with greater $D_{o} / d$. 

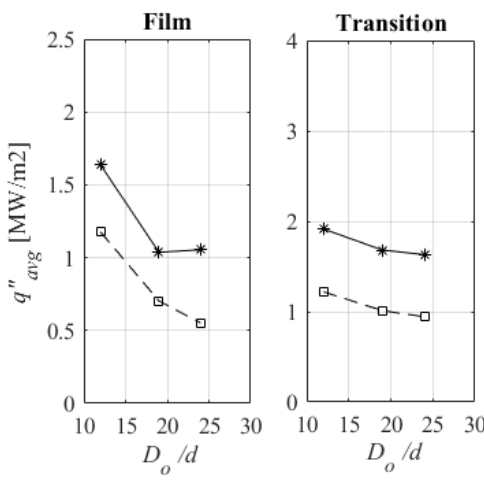

(a)

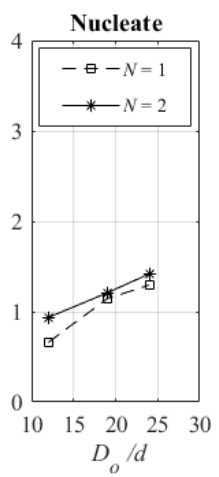

$D_{0} / d$

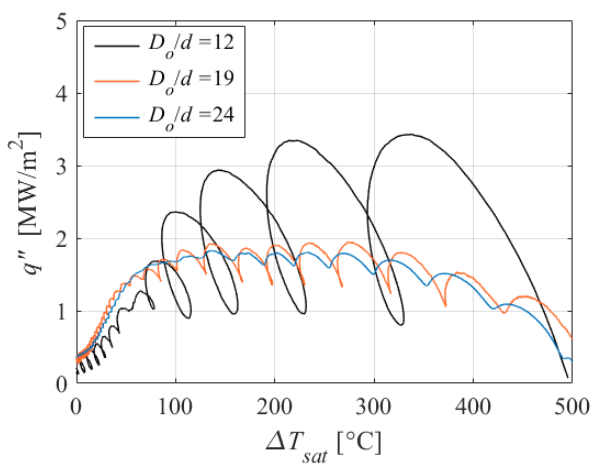

(b)

Fig 8: Curvature aspect ratio's $\left(D_{o} / d\right)$ influence on local heat transfer at $x_{s t g}$; (a) $q^{\prime \prime}$ avg (b) boiling curves in the 2-row multiple jets array $\left(T_{i}=600^{\circ} \mathrm{C}, \omega=30 \mathrm{rpm}, Q=5.4 \mathrm{~L} / \mathrm{min}, \Delta T_{\text {sub }}=75 \mathrm{~K}, N=2\right)$.

\section{Conclusion}

This paper presented an experimental study of quenching rotary hollow cylinder by multiple water impinging jet arrays. The focus of the study was to investigate some important parameters on local and area-averaged heat transfer as well as understanding effect of pitch on boiling heat transfer by using 1- and 2-row multiple jet arrays in the experiments. The results showed that water jet's flow rate and curvature ratio of cylinder had significant effect on the average local heat transfer in the all boiling regimes at stagnation point of water impinging jet. Rotation speed influenced the average local heat transfer in the film and transition boiling regime. However significant effect of subcooling was found in the transition boiling regime. In study of local maximum heat flux $(M H F)$ during quenching, results showed that higher water flow rate, subcooling and larger number of rows in array enhances $M H F$ characteristics (higher heat flux and temperature and less time to reach the $M H F$ ). Lower rotation speed and smaller curvature ratio also provided similar effect on $M H F$ parameters.

The effect of pitch combined with other parameters was highly pronounced in the film and transition boiling than in the nucleate boiling regime. It was found that in constant total flow rate in the multiple jets array, there is a trade-off between number of rows in the array $(N)$ and water jet's flow rate in terms of local heat transfer rate and spatial variation of boiling heat transfer over quenching surface during quenching time; 1-row pitch provides slower heat transfer rate with lower spatial variation over the quenching surface while higher heat transfer level and shorter cooling time is achieved by 2-row array.

\section{Acknowledgements}

The authors acknowledge financial support by Swedish Energy Agency, Sweden's Innovation Agency Vinnova, Ovako Company (Hofors, Sweden) and University of Gävle, Sweden. The authors are thankful for the assistance received by personnel at the laboratory of University of Gävle, Sweden.

\section{References}

[1] A. K. Mozumder, M. Monde, and P. L. Woodfield, "Delay of wetting propagation during jet impingement quenching for a high temperature surface," International Journal of Heat and Mass Transfer, vol. 48, no. 25-26, pp. 5395-5407, $12 / / 2005$.

[2] N. Hatta, J.-i. Kokado, and K. Hanasaki, "Numerical Analysis of Cooling Characteristics for Water Bar," Transactions of the Iron and Steel Institute of Japan, vol. 23, no. 7, pp. 555-564, 1983.

[3] N. Karwa, T. Gambaryan-Roisman, P. Stephan, and C. Tropea, "Experimental investigation of circular free-surface jet impingement quenching: Transient hydrodynamics and heat transfer," Experimental Thermal and Fluid Science, vol. 35, no. 7, pp. 1435-1443, 10// 2011.

[4] N. Karwa, L. Schmidt, and P. Stephan, "Hydrodynamics of quenching with impinging free-surface jet," International Journal of Heat and Mass Transfer, vol. 55, no. 13-14, pp. 3677-3685, 6// 2012.

[5] H. Robidou, H. Auracher, P. Gardin, and M. Lebouché, "Controlled cooling of a hot plate with a water jet," Experimental Thermal and Fluid Science, vol. 26, no. 2-4, pp. 123-129, 6// 2002. 
[6] C. Agrawal, R. Kumar, A. Gupta, and B. Chatterjee, "Effect of jet diameter on the maximum surface heat flux during quenching of hot surface," Nuclear Engineering and Design, vol. 265, pp. 727-736, 2013.

[7] C. Agrawal, R. Kumar, A. Gupta, and B. Chatterjee, "Effect of jet diameter on the rewetting of hot horizontal surfaces during quenching," Experimental Thermal and Fluid Science, vol. 42, pp. 25-37, 2012.

[8] B. Wang, X. Guo, Q. Xie, Z. Wang, and G. Wang, "Heat transfer characteristic research during jet impinging on top/bottom hot steel plate," International Journal of Heat and Mass Transfer, vol. 101, pp. 844-851, 2016/10/01/ 2016.

[9] A. K. Mozumder, M. Monde, P. L. Woodfield, and M. A. Islam, "Maximum heat flux in relation to quenching of a high temperature surface with liquid jet impingement," International Journal of Heat and Mass Transfer, vol. 49, no. 17-18, pp. 2877-2888, 8// 2006.

[10] T. Kim, D.-W. Oh, K. H. Do, J. M. Park, and J. Lee, "Effect of Initial Temperature of a Cylindrical Steel Block on Heat Transfer Characteristics of Staggered Array Jets During Water Jet Quenching," Heat Transfer Engineering, vol. 36, no. 12, pp. 1037-1045, 2015/08/13 2014.

[11] K. Morisawa, J.-y. Nakahara, K. Nagata, H. Fujimoto, T. Hama, and H. Takuda, "Boiling Heat Transfer Characteristics of Vertical Water Jet Impinging on Horizontally Moving Hot Plate," ISIJ International, vol. 58, no. 1, pp. 140-145, 2018.

[12] M. Gradeck, A. Kouachi, A. Dani, D. Arnoult, and J. Borean, "Experimental and numerical study of the hydraulic jump of an impinging jet on a moving surface," Experimental thermal and fluid science, vol. 30, no. 3, pp. 193-201, 2006.

[13] S. Vakili and M. S. Gadala, "Boiling heat transfer of multiple impinging jets on a hot moving plate," Heat Transfer Engineering, vol. 34, no. 7, pp. 580-595, 2013.

[14] M. A. Kumar, M. Yuichi, and M. Masanori, "Experimental Study of Heat Transfer for a Rotating Cylinder Water Jet Impingement Quenching," Journal of Energy and Power Engineering, vol. 7, pp. 411-422, 2013.

[15] M. Jahedi, F. Berntsson, J. Wren, and B. Moshfegh, "Transient inverse heat conduction problem of quenching a hollow cylinder by one row of water jets," International Journal of Heat and Mass Transfer, vol. 117, pp. 748-756, $2 / / 2018$.

[16] S. Tsuboyama, T. Higashi, Y. Mitsutake, S.B. Illias, A. Mazumder, K. Tsubaki, M. Monde, "Characteristics of Transient Heat Transfer and Wetting Phenomena During Laminar Jet Quenching on Rotating Cylinder," Procedia Engineering, vol. 105, no. Supplement C, pp. 787-797, 2015/01/01/ 2015.

[17] A. K. Mozumder, Y. Mitsutake, and M. Monde, "Subcooled water jet quenching phenomena for a high temperature rotating cylinder," International Journal of Heat and Mass Transfer, vol. 68, no. 0, pp. 466-478, 1// 2014.

[18] M. Jahedi and B. Moshfegh, "Experimental study of quenching process on a rotating hollow cylinder by onerow of impinging jets," in 9th World Conference on Experimental Heat Transfer, Fluid Mechanics and Thermodynamics, Brazil, 2017, vol. 9, 2017.

[19] M. Jahedi and B. Moshfegh, "Quenching a rotary hollow cylinder by multiple configurations of water-impinging jets," International Journal of Heat and Mass Transfer, vol. 137, pp. 124-137, 2019/07/01/ 2019.

[20] S. Slayzak, R. Viskanta, and F. Incropera, "Effects of interaction between adjacent free surface planar jets on local heat transfer from the impingement surface," International journal of heat and mass transfer, vol. 37, no. 2, pp. 269-282, 1994.

[21] Y. Saad, Iterative methods for sparse linear systems. siam, 2003.

[22] D. E. Hall, F. P. Incropera, and R. Viskanta, "Jet impingement boiling from a circular free-surface jet during quenching: Part 1-single-phase jet," Journal of heat transfer, vol. 123, no. 5, pp. 901-910, 2001.

[23] M. Gradeck, A. Kouachi, M. Lebouché, F. Volle, D. Maillet, and J. L. Borean, "Boiling curves in relation to quenching of a high temperature moving surface with liquid jet impingement," International Journal of Heat and Mass Transfer, vol. 52, no. 5-6, pp. 1094-1104, 2// 2009.

[24] P. L. Woodfield, A. K. Mozumder, and M. Monde, "On the size of the boiling region in jet impingement quenching," International Journal of Heat and Mass Transfer, vol. 52, no. 1-2, pp. 460-465, 1/15/ 2009. 